\title{
Knowledge by Primary Care of mental health patients treated at outpatient specialized services: prevalence and associated factors
}

Carlos Alberto dos Santos Treichel ( $\nabla$ treichelcarlos@gmail.com )

State University of Campinas

loannis Bakolis

King's College London

Rosana Teresa Onocko Campos

State University of Campinas

\section{Research Article}

Keywords: Shared Care, Mental Health, Community Mental Health Services, Primary Care, Collaborative Care

Posted Date: March 3rd, 2021

DOl: https://doi.org/10.21203/rs.3.rs-256691/v1

License: (c) (i) This work is licensed under a Creative Commons Attribution 4.0 International License. Read Full License 


\section{Abstract \\ Background}

Although matrix support seeks to promote the integration of Primary Care with specialized mental health services in Brazil, little is known about the quantitative impact of this strategy on the sharing of cases between different levels of care. The aim of this study was to investigate the prevalence and factors associated with knowledge by Primary Care of mental health patients treated at outpatient specialized services in a medium-sized city in Brazil with recent implementation of matrix support.

\section{Methods}

This is a document-based cross-sectional study, conducted through the analysis of 1198 patients' medical records. Crude and adjusted associations with the outcome were explored using logistic regression.

\section{Results}

The prevalence of cases known by Primary Care was 40\% $(n=479)$. Evidence was found for associations between the outcome and the patients being over 30 years old, and referral by emergency or hospital services. There was, conversely, an inverse association between the outcome and status as a patient from the Outpatient Clinic or from the Psychosocial Care Center for psychoactive substance misuse.

\section{Conclusions}

Even with the provision of mechanisms for network integration, such as matrix support, our results suggest that more groundwork is necessary to ensure that the sharing of cases between Primary Care and specialized services is effective.

\section{Background}

Worldwide, efforts have been made to integrate specialized mental health services and Primary Care in order to reduce the treatment gap and offer better mental health care $[1,2]$.

A recently conducted literature review [3] synthesized evidence that patients receiving treatment in the integrated models tend to have better outcomes compared with those receiving regular care.

In high-income countries, different integration models have been classified based on the nature and level of coordination between providers. At the first level, patients are referred to another location (coordinated care). At the second level, providers provide care at the same location, but do not share treatment plans 
(colocated care). At the highest level of integration, providers are part of the same team with a common treatment plan, and the patient receives care within a single system (integrated care) $[3,4]$.

In Brazil, since 2008, attempts to integrate specialized mental health services and Primary Care have taken place through matrix support. Corresponding to an integrated care proposal, the matrix support service is a model of pedagogical-therapeutic intervention. It aims to produce and stimulate relationships among providers and patients, so as to foster the exchange of information and expansion of coresponsibility by the patient $[5,6]$.

However, although there have been significant contributions to the literature regarding facilitators and barriers to matrix support services [7,8], little is known about the system's quantitative impact on the sharing of cases between different levels of care [9].

A literature review regarding the pathways to mental health care in Brazil [10] has shown that most patients who reach specialized mental health services are referred by non-Primary Care services, with hospitals and emergency services often being the first point of contact with the formal health network.

Additionally, continuity of care, especially regarding the return of patients from specialized services to Primary Care, is a well-known problem in Brazil $[9,11]$. Thus, we hypothesized that a significant proportion of mental health patients treated in specialized services are not known to Primary Care. The aim of this study was to investigate the prevalence and factors associated with knowledge by Primary Care of mental health patients treated at outpatient specialized services in a medium-sized city in Brazil with recent implementation of matrix support.

\section{Methods}

\section{Design and participants}

This is a document-based cross-sectional study, conducted through the analysis of medical records of patients from outpatient specialized mental health services in a medium-sized city in Brazil. It is a city with approximately 120,000 inhabitants, $80 \mathrm{~km}$ (50 mi) away from São Paulo, which has three outpatient specialized mental health services, namely: Psychosocial Care Center-II (PCC-II), Psychosocial Care Center for Psychoactive Substance Misuse (PCC-PSM), and the Outpatient Clinic.

During the research period, 413 patients were registered in the PCC-II, 403 patients were registered in the PCC-PSM, and 1142 patients were receiving mental health consultations at the Outpatient Clinic.

Inclusion criteria were being of adult age and having at least one registration for a mental health appointment between May 2018 and May 2019.

Individuals were excluded if they resided in an area not covered by a Primary Care service that operates on the Family Health Strategy (FHS) model.

Ultimately, 1198 patient records were included in this study. 


\section{Data collection procedures}

Data collection procedures were developed at the services between May and July 2019 and delivered by 16 trained individuals. These individuals were selected undergraduate students or undergraduate professionals in psychology or medicine and were supervised by 2 undergraduate professionals, one in nursing and one in social assistance. Data collectors filled out a form prepared for the purposes of the research when inclusion criteria were met based on data available in the medical records.

\section{Primary Care database}

Before conducting this study, a database was created to compile Primary Care patients who had a record of complaints related to mental health. The inclusion of patients in this database considered the registration of at least one attendance due to mental health complaints with regard to section $\mathrm{F}$ of the International Statistical Classification of Diseases and Related Problems (ICD), or the registration of psychosomatic complaints associated with the use of a medicine belonging to group $\mathrm{N}$ of the WHO Anatomical Therapeutic Chemical Code (ATC) system. Among 60411 patients covered by a Primary Care service operating on the FHS model, 9834 patients were included in the database.

\section{Outcome}

Our outcome was the knowledge by Primary Care of mental health patients treated at outpatient specialized mental health services. To assess this outcome, all patients included in the study had their data cross-checked with data from the Primary Care database. Patients were considered positive if they had a record of mental health care in both Primary Care and specialized services.

\section{Covariates}

From the information included in medical records, the following variables were considered of interest for this study: sex (male; female); age (18 to 30 years; 31 to 45 years; 46 to 60 years; 61 + years); diagnosis (neurotic disorders; affective disorders - unipolar; affective disorders - bipolar; psychosis; psychoactive substance misuse; intellectual disability or organic disorders; developmental disorders; no current diagnosis); referral source to the current service (spontaneous demand; Primary Care; emergency or hospital services; private services); time attending the current service (up to 1 year; up to 3 years; up to 5 years; 5 + years).

\section{Statistical analysis}

Statistical analyses were conducted with the use of Stata 15 (Stata Corporation, College Station, Texas USA). Descriptive statistical analysis with absolute and relative frequency estimates was carried out for each of the covariates. There were no missing data for any of the studied variables.

Associations between the outcome - knowledge by Primary Care of mental health patients treated at outpatient specialized services - and covariates were tested using unadjusted and adjusted logistic regression models. Adjustment took place in a single step and considered all included covariates. 


\section{Ethical procedures}

The study was submitted and approved, under opinion No. 3.065.312, by the Ethics Committee of the School of Medical Sciences of the University of Campinas, following the Brazilian regulatory standards and guidelines for research involving human beings (CNS Resolution 466/2012).

It was similarly in accordance with the provisions of the Declaration of Helsinki. The study fully ensured patients' anonymity.

Informed consent was obtained by all study participants.

It adhered to the Guidelines for Strengthening the Reporting of Observational Studies in Epidemiology (STROBE Statement).

Results

\section{Characterization of the participants}

A total of 1198 patient records were included in this study, with 25\% $(n=299)$ from Psychosocial Care Center II (PCC-II), 19.4\% ( $n=232)$ from the Psychosocial Care Center for Psychoactive Substance Misuse (PCC-PSM), and $55.7 \%$ from the Outpatient Clinic. The characterization of participants in relation to study covariates, by service and overall, is given in Table 1 . 
Table 1

Descriptive statistics of participants $(n=1198)$.

\begin{tabular}{|c|c|c|c|c|c|c|c|c|}
\hline & \multicolumn{2}{|c|}{ PCC II } & \multicolumn{2}{|c|}{ PCC-PSM } & \multicolumn{2}{|c|}{$\begin{array}{l}\text { Outpatient } \\
\text { Clinic }\end{array}$} & \multicolumn{2}{|c|}{ Overall } \\
\hline & $\mathbf{n}$ & $\%$ & $\mathbf{n}$ & $\%$ & $\mathbf{n}$ & $\%$ & $\mathbf{n}$ & $\%$ \\
\hline \multicolumn{9}{|l|}{ Sex } \\
\hline Male & 130 & 43.5 & 180 & 77.6 & 201 & 30.1 & 511 & 42.7 \\
\hline Female & 169 & 56.5 & 52 & 22.4 & 466 & 69.9 & 687 & 57.3 \\
\hline \multicolumn{9}{|l|}{ Age } \\
\hline 18 to 30 years & 50 & 16.7 & 86 & 37.1 & 167 & 25.1 & 303 & 25.3 \\
\hline 31 to 45 years & 98 & 32.8 & 74 & 31.9 & 152 & 22.8 & 324 & 27.1 \\
\hline 46 to 60 years & 104 & 34.8 & 64 & 27.6 & 205 & 30.7 & 373 & 31.1 \\
\hline $61+$ years & 47 & 15.7 & 8 & 3.4 & 143 & 21.4 & 198 & 16.5 \\
\hline \multicolumn{9}{|l|}{ Diagnosis } \\
\hline Neurotic disorders & 33 & 11.0 & 9 & 3.9 & 271 & 40.7 & 313 & 26.1 \\
\hline Affective disorders (unipolar) & 40 & 13.4 & 2 & 0.8 & 92 & 13.8 & 134 & 11.2 \\
\hline Affective disorders (bipolar) & 52 & 17.4 & 5 & 2.2 & 12 & 1.8 & 69 & 5.8 \\
\hline Psychosis & 121 & 40.5 & 4 & 1.7 & 25 & 3.7 & 150 & 12.5 \\
\hline Psychoactive substance misuse & 8 & 2.7 & 74 & 31.9 & 17 & 2.5 & 99 & 8.3 \\
\hline $\begin{array}{l}\text { Intellectual disability or Organic } \\
\text { disorders }\end{array}$ & 28 & 9.4 & 4 & 1.7 & 36 & 5.4 & 68 & 5.7 \\
\hline Developmental disorders & 1 & 0.3 & 2 & 0.9 & 30 & 4.5 & 33 & 2.7 \\
\hline No current diagnosis & 16 & 5.3 & 132 & 56.9 & 183 & 27.5 & 332 & 27.7 \\
\hline \multicolumn{9}{|c|}{ Referral source for the current service } \\
\hline Spontaneous demand & 47 & 15.7 & 117 & 50.4 & 434 & 65.1 & 598 & 49.9 \\
\hline Primary Care & 64 & 21.4 & 29 & 12.5 & 205 & 30.7 & 298 & 24.9 \\
\hline Emergency or Hospital services & 35 & 11.7 & 7 & 3.0 & 2 & 0.3 & 44 & 3.7 \\
\hline Other specialized service & 141 & 47.2 & 19 & 8.2 & 7 & 1.1 & 167 & 13.9 \\
\hline Private Services & 12 & 4.0 & 60 & 25.9 & 19 & 2.8 & 91 & 7.6 \\
\hline
\end{tabular}

PCC-II: Psychosocial Care Center-Il; PCC-PSM: Psychosocial Care Center for Psychoactive Substance Misuse. 


\begin{tabular}{|c|c|c|c|c|c|c|c|c|}
\hline & \multicolumn{2}{|c|}{ PCC II } & \multicolumn{2}{|c|}{ PCC-PSM } & \multicolumn{2}{|c|}{$\begin{array}{l}\text { Outpatient } \\
\text { Clinic }\end{array}$} & \multicolumn{2}{|c|}{ Overall } \\
\hline \multicolumn{9}{|c|}{ Time attending the current service } \\
\hline Up to 1 year & 62 & 20.7 & 136 & 58.6 & 223 & 33.4 & 421 & 35.2 \\
\hline Up to 3 years & 52 & 17.4 & 30 & 12.9 & 161 & 24.1 & 243 & 20.3 \\
\hline Up to 5 years & 48 & 16.1 & 21 & 9.1 & 262 & 39.3 & 331 & 27.6 \\
\hline $5+$ years & 137 & 45.8 & 45 & 19.4 & 21 & 3.2 & 203 & 16.9 \\
\hline TOTAL & 299 & 100 & 232 & 100 & 667 & 100 & 1198 & 100 \\
\hline
\end{tabular}

\section{Primary Care knowledge of patients}

Overall, knowledge by Primary Care of mental health patients treated at outpatient specialized services was calculated to be $40 \%(n=479)$. According to a chi-square test (not in figure), there was evidence $(p<$ 0.001) of significant differences in the prevalence of the outcome among different outpatient specialized services. The prevalence of users who had their mental health issues recorded both in specialized services and Primary Care services according to each studied service are shown in Fig. 1.

The prevalence of the outcome with regard to each of the covariates included in the study was investigated, as well as associations between covariates and the outcome using adjusted and unadjusted logistic regression. The results of these analyses are shown in Table 2. 
Table 2

Unadjusted and adjusted ${ }^{\mathrm{a}}$ associations between studied variables and knowledge of the case by Primary Care are provided with the use of Logistic regression models. Odds Ratios (OR) with $95 \%$ corresponding confidence intervals (Cls) are presented $(n=1198)$.

\begin{tabular}{|c|c|c|c|c|}
\hline & $\mathrm{n}$ & $\%$ & $\begin{array}{l}\text { Unadjusted OR } \\
\text { (95\%Cl) }\end{array}$ & $\begin{array}{l}\text { Adjusted }{ }^{\mathrm{a}} \text { OR } \\
(95 \% \mathrm{Cl})\end{array}$ \\
\hline \multicolumn{5}{|l|}{ Sex } \\
\hline Male & 511 & 37.2 & 1 & 1 \\
\hline Female & 687 & 42.1 & $1.22(0.97-1.55)$ & $1.08(0.82-1.42)$ \\
\hline \multicolumn{5}{|l|}{ Age } \\
\hline 18 to 30 & 303 & 30.0 & 1 & 1 \\
\hline 31 to 45 & 324 & 43.2 & $1.77(1.27-2.46)$ & $1.48(1.03-2.10)$ \\
\hline 46 to 60 & 373 & 43.2 & $1.76(1.28-2.43)$ & $1.45(1.02-2.07)$ \\
\hline 61 or more & 198 & 43.9 & $1.82(1.25-2.65)$ & $1.56(1.03-2.36)$ \\
\hline \multicolumn{5}{|l|}{ Diagnosis } \\
\hline Neurotic disorders & 313 & 41.8 & 1 & 1 \\
\hline Affective disorders (unipolar) & 134 & 44.8 & $1.12(0.74-1.69)$ & $0.94(0.60-1.46)$ \\
\hline Affective disorders (bipolar) & 69 & 46.4 & $1.20(0.71-2.02)$ & $0.73(0.40-1.33)$ \\
\hline Psychosis & 150 & 50.0 & $1.38(0.93-2.05)$ & $0.88(0.53-1.43)$ \\
\hline Psychoactive substance misuse & 99 & 38.4 & $0.86(0.54-1.37)$ & $1.03(0.59-1.80)$ \\
\hline $\begin{array}{l}\text { Intellectual disability or Organic } \\
\text { disorders }\end{array}$ & 68 & 45.6 & $1.16(0.68-1.97)$ & $0.95(0.54-1.66)$ \\
\hline Developmental disorders & 33 & 21.1 & $0.37(0.15-0.88)$ & $0.51(0.20-1.27)$ \\
\hline No current diagnosis & 332 & 31.6 & $0.64(0.46-0.88)$ & $0.78(0.54-1.12)$ \\
\hline \multicolumn{5}{|l|}{ Current service } \\
\hline PCC-II & 299 & 54.2 & 1 & 1 \\
\hline PCC-PSM & 232 & 30.2 & $0.36(0.25-0.52)$ & $0.51(0.30-0.87)$ \\
\hline Outpatient Clinic & 667 & 37.0 & $0.49(0.37-0.65)$ & $0.59(0.37-0.92)$ \\
\hline \multicolumn{5}{|c|}{ Referral source to the current service } \\
\hline Spontaneous demand & 598 & 35.3 & 1 & 1 \\
\hline
\end{tabular}

a. Adjusted for sex; age; diagnosis; current service; referral source to the current service; time attending the current service. 


\begin{tabular}{|c|c|c|c|c|}
\hline & $\mathbf{n}$ & $\%$ & $\begin{array}{l}\text { Unadjusted OR } \\
(95 \% \mathrm{Cl})\end{array}$ & $\begin{array}{l}\text { Adjusted } \text { A OR } \\
(95 \% \mathrm{Cl})\end{array}$ \\
\hline Primary Care & 298 & 43.6 & $1.41(1.06-1.88)$ & $1.30(0.97-1.76)$ \\
\hline Emergency or Hospital services & 44 & 61.4 & $2.91(1.55-5.46)$ & $2.22(1.11-4.45)$ \\
\hline Other specialized service & 167 & 51.5 & $1.94(1.37-2.75)$ & $1.26(0.80-1.98)$ \\
\hline Private Services & 91 & 27.5 & $0.69(0.42-1.13)$ & $0.86(0.50-1.48)$ \\
\hline \multicolumn{5}{|l|}{ Time attending the current service } \\
\hline Up to 1 year & 421 & 34.9 & 1 & 1 \\
\hline Up to 3 years & 243 & 42.8 & $1.39(1.00-1.92)$ & $1.20(0.85-1.68)$ \\
\hline Up to 5 years & 331 & 39.6 & $1.22(0.90-1.64)$ & $1.02(0.72-1.45)$ \\
\hline $5+$ years & 203 & 47.8 & $1.70(1.21-2.39)$ & $1.08(0.71-1.63)$ \\
\hline
\end{tabular}

Evidence was observed for an association between knowledge of patients by Primary Care and older patient age. All age groups over 31 years presented higher odds ratios for the outcome: 31 to 45 (OR: 1.48; 95\% Cl: 1.03, 2.10); 46 to 60 (OR: 1.45; 95\% Cl: 1.02, 2.07); 61+ (OR: 1.56; 95\% Cl: 1.03, 2.36).

After adjustment, there was no evidence for differences in the outcome by diagnosis. However, we did observe an important difference related to the service that users were linked to. Namely, compared to PCC-II patients, we found an inverse association with the outcome among PCC-PSM patients (OR: 0.51; $95 \% \mathrm{Cl}: 0.30,0.87)$ and Outpatient Clinic patients (OR: 0.59; $95 \% \mathrm{Cl}: 0.37,0.92)$.

Finally, there was evidence for an association between referral by an emergency or hospital service to the current outpatient service, and knowledge of the case by Primary Care (OR: 2.22; 95\% Cl: 1.11, 4.45).

\section{Discussion}

As far as we are aware, this is the first study to explore and attempt to quantify knowledge by Primary Care of mental health patients treated at outpatient specialized services. This study is particularly important in the Brazilian context, given the model of functioning of its mental health network. In contrast to Cuba, Spain and the United Kingdom, middle and high income countries with a strong gatekeeping role by primary care and very low percentage of direct access (0-2.5\%) [12], although the Brazilian health system works on the stepped care model, its specialized outpatient mental health services provide access by spontaneous demand.

Another development that should be highlighted in the Brazilian context is the recent reinsertion of the Outpatient Clinic as a component of the psychosocial care network by Ordinance No. 3588 (instituted 
December 21, 2017). As a result of psychiatric reform movements, over four decades the Brazilian health system had shifted to operating in a manner more favorable to community mental health services, such as Psychosocial Care Centers. However, due to political disputes in recent years, biomedical practice increasingly dominates mental health care [13]. In Outpatient Clinics, this has been evidenced, historically, by the hierarchy among professionals and disarticulation among components of the mental health network $[13,14]$.

That mentioned above is relevant to understanding the results of the present study. It is noteworthy that the Outpatient Clinic and the PCC-PSM had the lowest prevalence of mental health patients known to Primary Care, while simultaneously demonstrating the highest percentage of patient intake by spontaneous demand.

Overall, knowledge by Primary Care of mental health patients treated in specialized services was $40 \%$, while among PCC-II patients, the prevalence was $54.2 \%$. In contrast, the Outpatient Clinic, rather than PCCII, had the highest proportion of patients referred by Primary Care, but a prevalence of mental health patients known to Primary Care of $37 \%$. It should be noted, however, that $47.2 \%$ of PCC-II patients were referred by other specialized services, mainly represented by the Outpatient Clinic. This scenario suggests a strongly centralized network at the Outpatient Clinic, which, despite being a specialized service, seems to function as a gateway to mental health care in the municipality studied.

In comparison, the proportion of direct access, (due to spontaneous demand) observed in our study, except for PCC-II, was higher than that found in countries such as Albania (40\%), India (40\%), Japan (39\%) and Romania (39\%), countries with the highest proportions of direct access among the 23 countries included in a review of pathways to mental healthcare worldwide[12].

Our criteria for determining the outcome included the recording of complaints related to mental health, a diagnosis report, or the use of psychotropic medications in the Primary Care records. Thus, it is assumed that some patients classified as negative for the outcome may have been assisted for other clinical conditions in Primary Care, even if their mental health treatment was not considered. Regardless, a scenario where only $40 \%$ of patients treated in specialized outpatient mental health services are known to Primary Care is troubling. Integrated teams depend on the exchange of complete, current, up-to-date information to enable independent and collaborative work by members across various professions [15].

The National Comorbidity Survey Replication, conducted in the United States of America, found that $68 \%$ of adults with mental health disorders also face physical health problems [16]. Considering a similar scenario in our context of interest, a lack of awareness by Primary Care regarding mental health patients seen in specialized services may result in patients with mental disorders not having their clinical needs adequately addressed. Alternatively, such a lack of awareness may indicate that the clinical care performed in Primary Care does not consider the totality of the health needs of the patient.

As with Outpatient Clinic patients, PCC-PSM patients were less likely to have their mental health needs known to Primary Care. It is noteworthy that historically, care for users of psychoactive substances has 
been taboo in Primary Care, as care in Brazil is organized in a territorial manner $[17,18]$. This is a problem especially for Community Health Agents (CHA), who are responsible for surveying patient needs [18]. Because they, by definition, live in the same community as their patients, these professionals do not wish to be mistaken as informants for the police or drug dealers [17]. Patients may themselves avoid seeking Primary Care for problems related to the use of psychoactive substances, although they occasionally access the service to obtain clinical health care $[17,19]$.

Another important factor is the growing presence of private services, such as Therapeutic Communities, as a component of the pathway to care for patients at the PCC-PSM. While a study conducted in MinasGerais, Brazil in 2016 [20] suggested a high prevalence of patients admitted through referral from other public services (44.7\%), in addition to spontaneous demand (43.7\%), our study identified a proportion of $25.9 \%$ of patients referred from private services. This is undoubtedly a topic that needs to be studied in greater depth. Therapeutic Communities promote the absence of the individual from society, are largely religious in nature, and many of them are not staffed by health professionals [21]. Thus, these services tend to use the equipment of the public health system, such as the PCC-PSM, to validate their treatments, but do not have the intention to integrate with other health network services, especially Primary Care.

In the current study, patients over 31 years of age were more likely to have their mental health needs known to Primary Care. This is in line with data from previous studies on the use of Primary Care [22]. Especially due to the higher incidence of chronic diseases, older patients may be more in need of the health care offered in Primary Care [23].

We found strong evidence for an association between being referred by an emergency or hospital service and having mental health needs known to Primary Care. These findings draw attention to important contradictions in the country's health network. If, on the one hand, the proportion of referrals by hospital and emergency services was low when compared to those found in studies from the United Kingdom (28.9\%) and Spain (24.3\%) [12], these referrals only happened after an inability to manage the case by primary care, which was not able to make the referral to the specialized service in a timely manner.

Our results suggest that although the context studied has a matrix support service, it is still incipient and has not been effective in promoting the sharing of cases between different levels of care.

There may be several factors that lead to the difficulty of operating this service. A literature review conducted previously [9] suggested that although it has been over 10 years since the implementation of matrix support in the Brazilian health system, it remains common for health networks to face problems such as: 1 ) lack of clarity in guidelines regarding the sharing of cases; 2 ) bureaucratization of the referral between services; 3 ) negative attitudes of professionals in dealing with mental health related issues; and 4) lack of institutionalized space and time for sharing of cases. It is noteworthy that these aspects are also highlighted in the study of international counterparts of this methodology, such as shared care [24].

Nonetheless, it is necessary to consider the important training gap in relation to mental health care experienced by both primary care and specialized care professionals [9]. The proportion of hours devoted to the study of mental health care in undergraduate medical curricula in Brazil is still low. A study 
conducted in Goiás [25] estimated that this proportion was $1.2 \%$ of the total hours of the course. In the field of nursing, a national review of undergraduate courses [26] concluded that the hours allocated to the study of mental health care corresponded to $2.4 \%$ in private institutions and $3.5 \%$ in public institutions.

Thus, it is necessary to create strategies to address this scenario. In addition to strengthening matrix support teams, bottom-up change should be implemented in order to establish a setting which promotes action by professionals. One important strategy may be to raise awareness and promote training of Primary Care professionals, especially $\mathrm{CHA}$, in identifying cases in a timely manner. It is also crucial for specialized services to improve the counter-referral of patients for Primary Care, thereby improving attainment of patient care and facilitating return of the patient from specialized to Primary Care.

Some limitations should be considered when interpreting our results. First, the incompleteness of data in the medical records limited the inclusion of information that could be relevant to studying the current outcome, such as ethnicity, income, paid work status, information on the screening of chronic diseases, and markers of social support, among others. Second, patients classified as negative for the outcome may have been assisted for other clinical conditions in Primary Care, even if their mental health condition was not considered. Nevertheless, our study provides valuable information for reorienting practice regarding the sharing of cases, both in the context studied and in other locations with similar arrangements.

\section{Conclusions}

In conclusion, we found evidence to support our hypothesis that a significant proportion of mental health patients seen in specialized services is not known to Primary Care. We observed associations of the outcome with patient age, and with referral source; namely, if patients were referred by an emergency or hospital service. At the same time, we observed an inverse association between the outcome and the patient's affiliation with the Outpatient Clinic or the Psychosocial Care Center for psychoactive substance misuse, suggesting important differences among the studied services and their relationship to the health network.

Our study provides relevant information for contexts where access to specialized mental health services occurs in different ways. The results demonstrate that even with the provision of mechanisms for network integration, such as matrix support, groundwork is necessary to ensure that the sharing of cases between primary care and specialized services is effective. We highlight the need to raise awareness among and improve the training of Primary Care professionals, as well as improve the counter-referral of patients from specialized services to primary care.

Our study also provides information on the proportion of patients with mental disorders who may not be receiving clinical care, contributing to the worsening of health disparities experienced by this population, especially with regard to psychotic patients and users of psychoactive substances. 


\section{List Of Abbreviations}

ATC: Anatomical Therapeutic Chemical Code

CHA: Community Health Agents

FHS: Family Health Strategy

ICD: International Classification of Diseases

PCC-II: Psychosocial Care Center II

PCC-PSM: Psychosocial Care Center for Psychoactive Substance Misuse

\section{Declarations}

\section{Ethics approval and consent to participate}

The study was submitted and approved, under opinion No. 3.065.312, by the Ethics Committee of the School of Medical Sciences of the University of Campinas, following the Brazilian regulatory standards and guidelines for research involving human beings (CNS Resolution 466/2012). It was similarly in accordance with the provisions of the Declaration of Helsinki. Informed consent was obtained by all study participants.

\section{Consent for publication}

Not applicable.

\section{Availability of data and materials}

The datasets generated and analysed during the current study are not publicly available due to ethical concerns regarding privacy and confidentiality of participants but are available from the corresponding author on reasonable request.

\section{Competing interests}

The authors declare that they have no competing interests.

\section{Funding}

Coordenação de Aperfeiçoamento de Pessoal de Nível Superior (CAPES) - Finance Code 001; Fundação de Amparo à Pesquisa do Estado de São Paulo (FAPESP), process n² 2018/10366-6.

\section{Authors' contributions}


CAST worked on the conception and design of the study, analysis and interpretation of data, writing and critical review of the manuscript. IB worked on the conception and design of the study, analysis and interpretation of data and critical review of the manuscript. RTOC worked on the conception and design of the study, interpretation of data and critical review of the manuscript.

\section{Acknowledgements}

This study was partly funded by the Coordenação de Aperfeiçoamento de Pessoal de Nível Superior Brasil (CAPES) - Finance Code 001. The research that originated this study was funded by the Fundação de Amparo à Pesquisa do Estado de São Paulo (FAPESP), process n² 2018/10366-6.

\section{References}

1: World Health Organization (2010) MhGAP intervention guide for mental, neurological and substance use disorders in non-specialized health settings: Mental Health Gap Action Programme (mhGAP). WHO. Genebra.

2: Kates N, Arroll B, Currie E, Hanlon C, Gask L, Klasen H et al. Improving collaboration between primary care and mental health services. The World Journal of Biological Psychiatry. 2018;20(10):748-765. doi: $10.1080 / 15622975.2018 .1471218$

3: Cubillos L, Bartels S, Torrey W, Naslund J, Uribe-Restrepo J, Gaviola C et al. The effectiveness and costeffectiveness of integrating mental health services in primary care in low- and middle-income countries: systematic review. BJPsych Bulletin. 2020;45(1):40-52. doi: 10.1192/bjb.2020.35

4: Integrated Health COE - National Council [Internet]. National Council. 2021 [cited 3 May 2020]. Available from: https://www.thenationalcouncil.org/integrated-health-coe/

5: Campos G. Equipes de referência e apoio especializado matricial: um ensaio sobre a reorganização do trabalho em saúde. Ciência \& Saúde Coletiva. 1999;4(2):393-403. doi: 10.1590/s141381231999000200013

6: Campos G, Domitti A. Apoio matricial e equipe de referência: uma metodologia para gestão do trabalho interdisciplinar em saúde. Cadernos de Saúde Pública. 2007;23(2):399-407. doi: 10.1590/S0102$311 \times 2007000200016$

7: Hirdes A, Silva M. Apoio matricial: um caminho para a integração saúde mental e atenção primária. Saúde em Debate. 2014;38(102):582-592. doi: 10.5935/0103-1104.20140054

8: Castro C, Campos G. Apoio Matricial como articulador das relações interprofissionais entre serviços especializados e atenção primária à saúde. Physis: Revista de Saúde Coletiva. 2016;26(2):455-481. doi: 10.1590/S0103-73312016000200007 
9: Treichel C, Campos R, Campos G (2019) Impasses e desafios para consolidação e efetividade do apoio matricial em saúde mental no Brasil. Interface - Comunicação, Saúde, Educação, 23. doi:

10.1590/interface.180617

10: Amaral C, Onocko-Campos R, de Oliveira P, Pereira M, Ricci E, Pequeno M et al (2018) Systematic review of pathways to mental health care in Brazil: narrative synthesis of quantitative and qualitative studies. International Journal of Mental Health Systems, 12(1). doi: 10.1186/s13033-018-0237-8

11; Vannucchi A, Carneiro Junior N (2012) Modelos tecnoassistenciais e atuação do psiquiatra no campo da atenção primária à saúde no contexto atual do Sistema Único de Saúde, Brasil. Physis: Revista De Saúde Coletiva, 22(3): 963-982. doi: 10.1590/s0103-73312012000300007

12: Volpe U, Mihai A, Jordanova V, Sartorius N (2015) The pathways to mental healthcare worldwide. Current Opinion in Psychiatry, 28(4), 299-306. doi: 10.1097/yco.0000000000000164

13: Onocko-Campos R. Saúde mental no Brasil: avanços, retrocessos e desafios. Cadernos de Saúde Pública. 2019;35(11). doi: 10.1590/0102-311x00156119

14: Severo A, Dimenstein M. Network and intersectorality in the psychosocial attention: contextualizing the role of the mental health clinic. Psicologia: Ciência e Profissão. 2011;31(3):640-655. doi:

$10.1590 / \mathrm{s} 1414-98932011000300015$

15: Cifuentes M, Davis M, Fernald D, Gunn R, Dickinson P, Cohen D. Electronic Health Record Challenges, Workarounds, and Solutions Observed in Practices Integrating Behavioral Health and Primary Care. The Journal of the American Board of Family Medicine. 2015;28(Supplement 1): S63-S72. doi:

10.3122/jabfm.2015.s1.150133

16: Alegria M, Jackson J, Kessler R, Takeuchi D. United States National Comorbidity Survey: Replication 2001-2003 | GHDx [Internet]. Ghdx.healthdata.org. 2015 [cited 1 May 2020]. Available from:

http://ghdx.healthdata.org/record/united-states-national-comorbidity-survey-replication-2001-2003

17: Paula ML, Jorge MSB, Vasconcelos MGF, Albuquerque RA (2014) Assistance to the drug user in the primary health care. Psicologia em Estudo, 19(2): 223-233. doi: 10.1590/1413-737222025006

18: Souza F, Ronzani T. Challenges to Harm Reduction Practices in Primary Health Care. Psicologia Em Estudo. 2018;23:59-68. doi: 10.4025/psicolestud.v23i0.37383

19: Filho AJT (2016) Approach to drug use in Primary Care - an awareness. Revista Médica de Minas Gerais, 26 (Supplemet 8):S11-S14.

20: Trevisan E, Castro S. Psychosocial Care Centers - alcohol and drugs: users' profile. Saúde Em Debate. 2019;43(121):450-463. doi: 10.1590/0103-1104201912113 
21: Guimaraes T, Rosa L. A remanicomialização do cuidado em saúde mental no Brasil no período de 2010-2019: análise de uma conjuntura antirreformista. O Social em Questão, 2019;44(2):111-138.

22: Guibu I, Moraes J, Guerra Junior A, Costa E, Acurcio F, Costa K et al. Main characteristics of patients of primary health care services in Brazil. Revista de Saúde Pública. 2017;51(suppl.2). doi:

$10.11606 / \mathrm{s} 1518-8787.2017051007070$

23: Schenker M, Costa D. Advances and challenges of health care of the elderly population with chronic diseases in Primary Health Care. Ciência \& Saúde Coletiva. 2019;24(4):1369-1380. doi: 10.1590/141381232018244.01222019

24: Kelly B, Perkins D, Fuller J, Parker S. Shared care in mental illness: A rapid review to inform implementation. International Journal of Mental Health Systems. 2011;5(1):31. doi: 10.1186/1752-44585-31

25: Carneiro L, Porto C. Mental health in undergraduate courses - its interface with National Curriculum Guidelines and with the Psychiatric Reform. Cadernos Brasileiros de Saúde Mental. 2014;6(14):150-167.

26: Vargas D, Maciel M, Bittencourt M, Lenate J, Pereira C. Teaching psychiatric and mental health nursing in Brazil: curricular analysis of the undergraduation course. Texto \& Contexto - Enfermagem. 2018;27(2):e2610016 doi: 10.1590/0104-070720180002610016

\section{Figures}

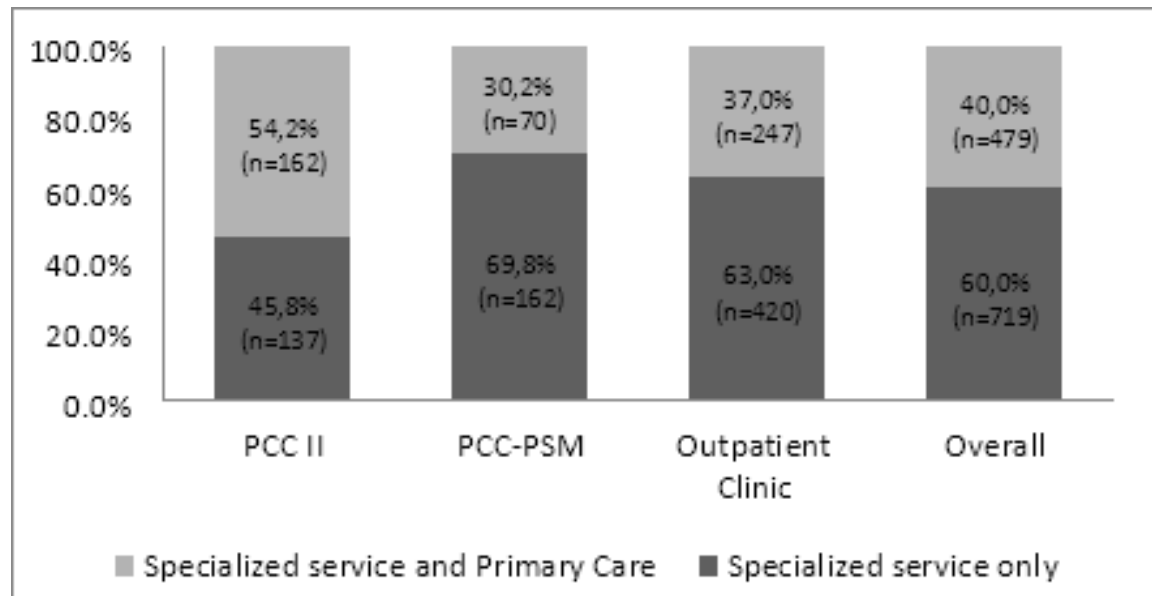

Figure 1

Prevalence of knowledge by Primary Care of mental health patients treated at the outpatient specialized services included in the study ( $n=1198)$. Source: The authors, 2019. PCC-II: Psychosocial Care Center-Il; PCC-PSM: Psychosocial Care Center for Psychoactive Substance Misuse. 